\title{
Talent Management as a Tool for Retaining Employee in the organization: A Study on Bangladesh
}

\author{
Dr. Mohammad Rahim Uddin \\ Assistant Professor, Department of Business Administration, International Islamic University Chittagong
}

\begin{abstract}
Scarcity of efficient and talented workforce is important challenges for the organization mostly available in developing countries like Bangladesh. Pressure from globalization and economic integration, retaining talent human resources are the strategic challenges for most of the organization. This study aimed to empirically test a talent management model developed from the literature review in the organization available in Bangladesh. In the model HR practices and employee attitudes towards organization were considered for the independent variable and decision of the employee to stay in the organization was considered for the dependent variable. Primary data was gathered from the employee working in management level at different manufacturing, service, and government organization. Descriptive statistics using SPSS 22 was applied to analyze the relationships among the study variable. Results from the analysis showed that HR practices and employee attitudes towards organizational satisfaction and pride have a significant influence on the decision of the employee to stay in the organization. HR practices have a substantial direct association with the decision of the employee to remain in the organization. At the same, HR practices was found indirectly associated with employee decides to stay through employee attitudes. Findings of the current research are expected to add value in the existing literature and deliver guideline for the manager struggling for keeping talent in the organization.
\end{abstract}

Keywords: HR practices, Employee attitudes, Retention, Talent management

DOI: $10.7176 / \mathrm{EJBM} / 11-21-21$

Publication date:July $31^{\text {st }} 2019$

\subsection{Introduction}

Role of Human resources in the organization has changed remarkably over the last few years. Earlier Human Resource department solely concentrated on general tasks like hiring, training, compensating, and benefit management. But later on, the HR department started to think strategically for the long term betterment of the organization. Strategic decisions like organizational development through training, corporate communications, and benefits management started being essential functions of the HR department. By this time, the HR department faces challenges to keep and maintain their human resources. Lack of supervisor support and inappropriate compensation was the prime reason for employee turnover in the banking sector in Bangladesh (Mahmud \& Idrish, 2011). Compensation and benefits management, supervisory support, the security of job are the crucial issues for the turnover of the academic faculty member in the non-government universities of Bangladesh (Joarder, 2012). So managing talent people is one of the significant challenges to gain strategic advantages in the organization looking for smooth growth in Bangladesh. Talent management focuses on strategic recruiting, development through training, and ensuring the continuous supply of dynamic leadership through succession planning. Significant functions of talent management include dealing scarcity and excess of talent, proper placement of talent, and compensating by maintaining the global standard. The success of organization in the competitive economy mostly depends on retaining talented people. In the later part, theoretical elaboration is presented to support the current research.

\subsection{Theoretical background}

Talent management is an old concept for the non-business organization. It was popular in the field of sports and entertainment at the end of the 18th century (Simonton, 2011). In the business sector, managing talent people is a new concept. The concept of talent management started to being popular after when McKinsey wrote the theory named "The War for Talent" at the 1990s (Michaels, Handfield-Jones, \& Axelrod, 2001). The method focuses on the on high demand and shortage of supply of talent people at high tech period. After the introduction of this groundbreaking many HR practitioners, consultant, and researcher feel the imbalance trend of talent supply. Several types of research had been conducted to examine the shortage of talented people (Tarique \& Schuler, 2010). As a consequence of the research the research, the phrases "acquisition and retention of talent," "attracting and developing talent" became common and popular among the HR management society. At present practitioner and business, executive agree that building a pipeline of strong talent, placing, and retaining them is a challenge for the organization. The researcher had conducted a survey on three hundred firms about managing talent human resources. The output of the research found that selecting an appropriate quantity of leader is the prime challenges 
and every year demand for talent leader is increasing every year, and it will continue in future also (Maxwell, 2006). The global environment and business completion are becoming more complex day by day. Managing global standards of the human resource, diversity of the workforce, and cultural and geographical differences are the prime challenges for managing talent workforce (Schuler, Jackson, \& Tarique, 2011). Now it is a prime concern for HR leaders and consultants to maintain global standards of a talented workforce (Stahl et al., 2012; Vaiman, Scullion, \& Collings, 2012).

\subsection{Model of the study}

Work-related state of mind and positive engagement of employee mostly depends on working energy, devotion, and dedication of employee (Schaufeli \& Bakker, 2004). Proposed study model in the present study was prepared based on the study model shown by Thomas and Tymon in 2009 (Thomas \& Tymon Jr, 2009) that was first published in 1993 (Thomas \& Tymon, 1993). The study considers six variables for talent management named as intrinsic rewards, employee performance management, corporate social responsibility, support from the manager, pride in the organization, and hygiene factors (Thomas, 2009). Employee satisfaction was found associated with HR practices that measured by satisfaction with organization and pride in the organization (Doh, Stumpf, Tymon, \& Haid, 2008). In the current study, HR practices are considered for input variable relevant to talent management practices. Four components were included to measure the satisfaction of HR practices. The components are Performance management, Professional development, Management support, and social responsibility.

The output variable Employee decision to stay in the organization is considered as the output variable. Three items were used to measure the employee decides to remain in the organization. Employee attitude was measured by two components named as pride in organization and satisfaction with the organization. All the items of the study model were taken from the scale developed by Thomas and Tymon (2009). The proposed study model based on literature is shown in figure 1 in the following.

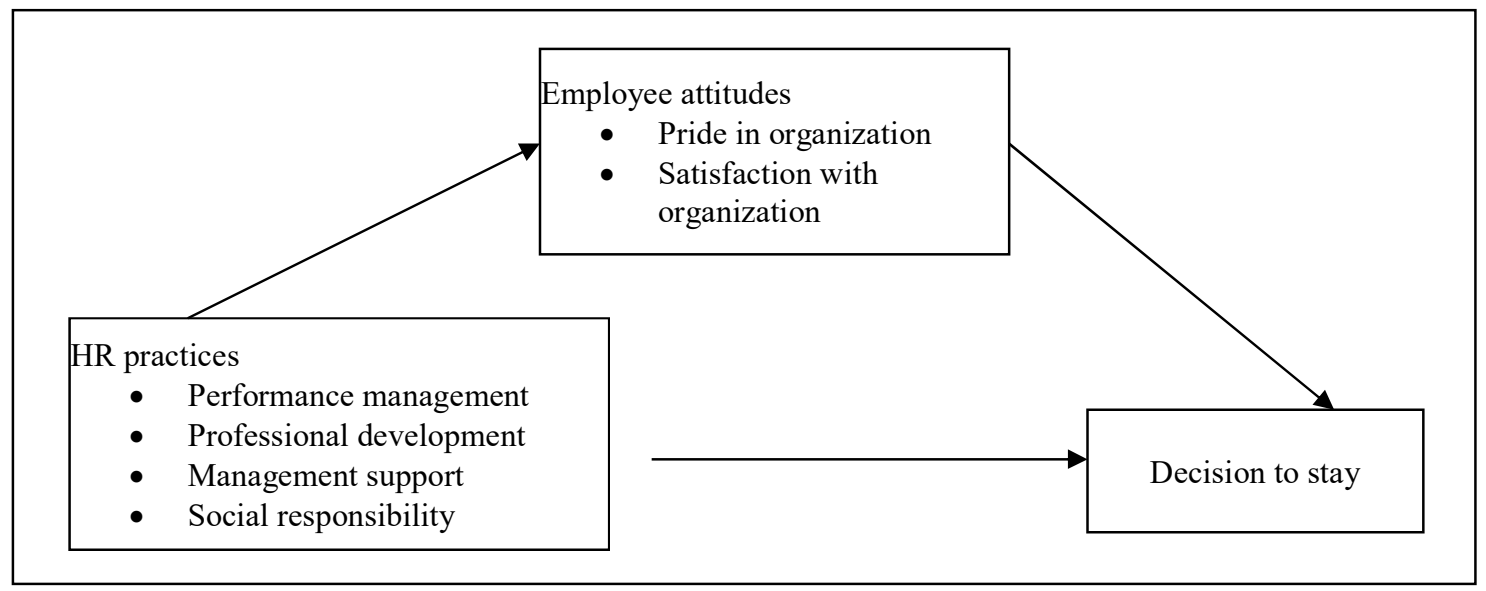

Figure 1. The Conceptual Framework

\subsection{Research Objectives}

The present study conducted to analyze the relationship between Human Resource practices and employee decision to remain in the organization. Review from the literature reveals that HR practices influence employee decides to stay or leave from in the organization. The study will provide both managerial and practical suggestions in planning and executing the talent management strategies to reduce employee turnover and intention to leave from the organization. The specific objectives are as follows:

1. To assess the HR practices and employee intention to stay in the organization.

2. To measure the association between HR practices and the employee decides to stay in the organization.

3. To ascertain whether employee attitude has any mediation role between the association of HR practices and the employee decides to stay in the organization. 


\subsection{Study Hypothesis \\ 5.1 HR practice}

Good performance management (PM) system is vital for motivating the employee to take challenges. Justice and faith in Performance Management may be crucial for engaging employee in work. Sound PM system informs and shows the way to employees to have employees experience of challenges in the accomplishment of their job (Macey \& Schneider, 2008). A significant connection was found between an accurate valuation of a firm's performance management system and employee retention. Good performance management practices increase pride and create excellent job satisfaction. A satisfied employee wants to keep him with the organization for a long time (Doh et al., 2008).

Development opportunity for future carrier increases the employee satisfaction leading to retaining talent employee with the organization. Past research also got similar results that suggest that employee assumption about good carrier success negatively associated with employee intention leave from the organization (Taylor, Audia, \& Gupta, 1996). The employee shows more effort when they have specific prospects for their career growth. Opportunities for career path include chances to have experienced with different projects, having opportunities for an overseas assignment and role for managerial responsibility. Employees that are not satisfied with the current opportunities for career growth have high intention leave from the organization (Doh et al., 2008).

A non-monetary advantage like a favorable working environment and career guide highly motivate employee for their continuation with the organization. Managerial mentoring to the employee associated with employee career satisfaction leading to career advancement (Allen, Eby, Poteet, Lentz, \& Lima, 2004). Duration of Employee Engagement with the organization also associated with good leadership (Macey \& Schneider, 2008). Employees who have the leader or manager with inefficient managerial and leadership skills are more likely to leave from the organization. An administrative gap in performance has a negative impact on employee decision to move from the organization (Doh et al., 2008). Managerial support provides knowledge to the workers to have experience of intrinsic rewards.

Social responsibility of the organization enhances employees' spirits, dedication, and trustworthiness (Branco \& Rodrigues, 2006). Corporate Social Responsibility stimulated identification engenders outcomes such as more significant employee commitment to work, high levels of ethics and morality, a devotion to excellence in job performances, job satisfaction, feelings of well-being, and a good sense of pride (Bhattacharya, Sen, \& Korschun, 2008).

The study assumes the following hypothesis based on past research.

H1: The mean score of HR practices is positively associated with the mean score of employee decision to stay in the organization.

H2: The mean score of HR practices is positively allied with the mean score of employee attitude towards the organization.

Good experience of intrinsic rewards, positively assessed Performance Management practices has a direct link with employee satisfaction with the organization, and career success. Positively perceived Performance Management practices directly affect employee attitudes (Nishii, Lepak, \& Schneider, 2008). Attention to social responsibility reflected in the attitudes of employees. An employer can be a vital source of pride to its employees by confirming social responsibility.

H3: Employee attitude is positively associated with employee decision to stay in the organization.

H4: Employee attitude mediate the association between HR practices and the decision to stay.

\subsection{Participants and procedure}

Present research comprised of general demographics questions as to age, gender, experience, etc., query about employee decision to stay with the current employer, HR practices, and employee attitudes about their organization. The population of this study covers all manufacturing and service organization mainly located at Chittagong Metropolitan Area in Bangladesh.

Area sampling method was applied to collect the primary data from the respondents. For designing geographic clusters, area sampling is highly acceptable (Sekaran, 2003). There is different manufacturing, service, government, and non-government organization available in the selected area. Among the different organization, thirteen manufacturing, nine private, and six government organization were communicated for the sample data.

A cover letter explaining the purpose of the study was attached to the distributed questionnaire. Prior consent of the respondent was taken before delivering the survey. The response rate was $85 \%$ for this study. The survey documents were distributed through email and hard copy personally to the respondent.

The majority of the sample was male (62\%), while it was less than half (38\%) were represented by female respondents. However, most of the respondents were 31 to 40 years old, while the majority of the respondents had 
seven years of experiences. Thirty-eight percent of respondents were from the middle level, where 28 percent were from the top level employee in the organization.

\subsection{Measures}

Analysis of the present research was prepared based on Quantitative research designs. Conceptual framework of the study developed based on literature studies. The quantitative research, in the form of a questionnaire with 7 point Likert scale numbered from 1(strongly disagree) to 7 (strongly agree) to indicate how much agree or disagree with each statement. For the quantitative part of the study, questionnaire surveys, the personal interviewing technique is employed. The items were developed by Thomas and Tymon in 2009 and it was first published in 1993, and has proven to be reliable and valid measures (Jandaghi, 2014; K. Thomas \& Tymon Jr, 2009; K. W. Thomas \& Tymon Jr, 1997). Descriptive statistics and regression analysis are applied to analyzing the study variable.

The scale measuring HR practices contained four components as Performance management, Professional development, Management support, and Social responsibility with four items for each component expressing the extent to which a person satisfies about HR practices. The internal consistency was adequate (Cronbach's alfa $(\alpha)$ $=0.94)$.

Employee attitudes consist of two components as satisfaction with organization and pride in the organization. Each component had four items for each. Cronbach's $\alpha$ for the scale was 0.77.

Three items measured the scale Employee decision to stay in the organization. The internal consistency of this scale was adequate (Cronbach's $\alpha=0: 80$ ). The value of scale reliability is shown in table 1 in the following.

\subsection{Results}

Descriptive statistics of the sample and variable presented showing Means, standard deviations, and Pearson correlations among the variables in Tables 1 . Correlation among the study variable are good but not to the extent that would suggest multicollinearity. Thus, the study proceeded with hypothesis tests.

Table 1: Means, Standard Deviations and Pearson Correlations of all variables

\begin{tabular}{lccc}
\hline \multicolumn{3}{c}{ Pearson Correlation } \\
\hline HR Practice & $.94[4]$ & Employee attitude & Decision to Stay \\
Employee attitude & $.884^{* *}$ & $.77[2]$ & \\
Decision to Stay & $.596^{* *}$ & $.856^{* *}$ & $.80[3]$ \\
\hline Mean & 4.07 & 4.05 & 4.67 \\
Std. Deviation & 1.49 & 1.40 & .99 \\
\hline N $=504, * * p<0.01, * p<0.05$ & & \\
Note: Cronbach Alpha estimates of reliability and number of items in [brackets] had shown in the diagonal \\
line.
\end{tabular}

\subsection{Hypothesis testing}

\subsection{Testing Hypothesis H 1}

The first hypothesis proposed that the mean score of HR practices is positively associated with the mean score of employee decision to stay in the organization. The study performed ANOVA, which exposed a main effect of HR practices $(F(1,502)=276.831, p=0.000)$, with $R 2=0.355$. In the scope of the findings, it was found that HR practices had positive and significant $(B=.596, \mathrm{p}=0.000)$ effect on the Employee decision to stay in the organization. So there is evidence in favor of assumed null hypothesis (H1) that the mean score of HR practices is positively associated with the mean score of employee decision to stay in the organization.

\subsection{Testing Hypothesis 2}

Hypothesis 2 proposed the mean score of HR practices is positively allied with the mean score of employee attitude towards the organization. Result from the $\operatorname{ANOVA}\left(\mathrm{F}(1,502)=1792.959, \mathrm{p}=0.000\right.$, with $\mathrm{R}^{2}$ $=0.78)$ shows that HR practice have a significant effect $(\beta=.88, p=0.000)$ on employee attitude. Findings of the analysis support the proposed hypothesis. 


\subsection{Testing hypothesis 3}

The third hypothesis expressed the expectation that Employee attitude is positively associated with employee decision to stay in the organization. Indeed, using $\operatorname{ANOVA}\left(\mathrm{F}(1,502)=1792.959, \mathrm{p}=0.000\right.$ and $\mathrm{R}^{2}=$ $.73)$ it is found significant differences for employee attitude such that Employee attitude have significant impact $(ß=.85, p=0.000)$ on employee decision to stay in the organization. Therefore, hypothesis three was confirmed

\section{Mediation effect}

The study had conducted mediation analysis using employee attitude as a mediator to check the indirect effect of HR practice on employee decision to stay in the organization. Baron and Kenny (1986) model was used to analyze the mediation effect (Baron \& Kenny, 1986). Results from the previous three hypotheses support all the precondition of the Baron and Keny (1986) has been supported for conducting mediation analysis. The three paths had found significant in the analysis result table 2 prove that indirect effect from HR practice to employee decision to stay in the organization is true. There is a partial mediation effect had been occurred by the employee attitude in the association between HR practice and employee decision to stay in the organization. Sobel test (1982) has been applied to see the appropriateness of mediation effect (Sobel, 1982). The test statistic score $(z=29.23, p$ $<.05)$ of the Sobel test is found significant.

Table 2: Regression Statistics for Mediation Analysis

\begin{tabular}{lccrrrrr}
\hline & & & Unstandardized & Standardized \\
& & Estimate & Estimate (ß) & S.E. & C.R. & P \\
\hline Employee attitude & $<---$ & HR practice & .831 & .884 & .020 & 42.385 & $* * *$ \\
Decision to stay & $<---$ & HR practice & -.491 & -.7351 & .025 & -20.016 & $* * *$ \\
Decision to stay & $<---$ & Employee attitude & 1.070 & 1.506 & .026 & 41.012 & $* * *$ \\
\hline
\end{tabular}

\section{Direct, indirect, and total effect from the mediation}

The direct and indirect effect of HR practices on employee decision to stay due to the mediation effect is presented in table 3 .

Table 3: Direct, indirect, and total effect

\begin{tabular}{llll}
\hline & $\begin{array}{c}\text { Direct effect on } \\
\text { employee decision to } \\
\text { stay }\end{array}$ & $\begin{array}{c}\text { Indirect effect on } \\
\text { employee decision to } \\
\text { stay }\end{array}$ & $\begin{array}{c}\text { Total effect on } \\
\text { employee decision to } \\
\text { stay }\end{array}$ \\
\hline HR practices & -.735 & 1.331 & .596 \\
Employee attitude & .884 & .000 & .884 \\
\hline
\end{tabular}

The total direct effect from HR practices to employee decision to stay in the organization is found 0.035 , and indirect impact through employee attitude is 0.093 . And hence, the overall effect of HR practices on employee decision to stay in the organization is 0.128 .

\subsection{Discussion}

The present study investigated the cause of decision about employee engagement in the organization. A model was prepared (fig 1) based on literature was develop to study talent management practices in Bangladesh. Three hypotheses were assumed to analyze the objectives of the study. And finally, mediation analysis was conducted to check the indirect effect of HR practices on employee decision to stay in the organization. The study prediction was HR practices, and employee attitude is associated with employee decision to remain in the organization. The findings of the study support the prediction of the study.

The first hypothesis assumed to analyze the relation between HR practices and employee decision to stay in the organization. Four components as Performance management, Professional development, Management support, Social responsibility was considered to measure employee satisfaction about HR practices. The mean score was significantly associated with employee decision to stay in the organization. Current findings are relevant to past research also. Organizational social responsibility (CSR) activities encompass a valid and essential manner to retain efficient employee (Bhattacharya et al., 2008). Effective performance management systems guide employees for experiencing challenge and update for intrinsic rewards in performing their job. Sound performance 
system emphasizes fairness and confidence that important to engage employees in the organization (Macey \& Schneider, 2008).

Second hypothesis supposed to measure the effect of HR practices on employee attitude. Results from the analysis showed that HR practices had a significant association with employee attitude towards the organization. Hygiene factors external to the job have an association with perceptions of employee and attitude towards work. Satisfaction about compensation, job location, and company benefits positively influence employee attitude (Herzberg, 1966). Attention to social responsibility reflects the attitudes of the employees. Other research does suggest the likelihood of a direct effect of positively perceived PM practices on employee attitudes (Nishii et al., 2008).

Third hypothesis supposed to analyze the relationship between employee attitudes and decision to stay in the organization. Results from the analysis indicate that a good association between employee attitudes and decision to remain in the organization. Work engagement is a causal antecedent of the number of organizationally relevant outcomes like work satisfaction (Liden, Wayne, \& Sparrowe, 2000) and commitment to the organization.

Finally, the study made an effort to see the mediating role of employee attitude in determining the indirect effect from HP practices to employee retention with the organization. The indirect impact was also significant. Here it is found that HR practices both directly and indirectly influences the retention of the employee with the organization.

\subsection{Conclusion}

Present study inspected a study model that projected relationships of HR practices, employee attitude towards the organization, and retention of the employee in the organization. Findings of the study demonstrate significant association among the study variable. Creating a favorable environment using good HR practices and positive attitude towards the organization will help the employer retain their employee for the long-run. Bangladesh to become globally competitive, it is essential to emphasize HR practices that create positive employee attitude towards their organization for the aims of developing strategies to retain talented employees.

\section{Reference}

Allen, T. D., Eby, L. T., Poteet, M. L., Lentz, E., \& Lima, L. (2004). Career benefits associated with mentoring for protégés: A meta-analysis. Journal of Applied Psychology, 89(1), 127.

Baron, R. M., \& Kenny, D. A. (1986). The moderator-mediator variable distinction in social psychological research: Conceptual, strategic, and statistical considerations. Journal of personality and social psychology, 51(6), 1173.

Bhattacharya, C. B., Sen, S., \& Korschun, D. (2008). Using corporate social responsibility to win the war for talent. MIT Sloan Management Review, 49(2).

Branco, M. C., \& Rodrigues, L. L. (2006). Corporate social responsibility and resource-based perspectives. Journal of business Ethics, 69(2), 111-132.

Doh, J. P., Stumpf, S. A., Tymon, W., \& Haid, M. (2008). How to retain talent in India. MIT Sloan Management Review, 50(1), 6-7.

Herzberg, F. I. (1966). Work and the nature of man.

Jandaghi, G. (2014). Talent Development in light of Satisfaction and Career Success. Dissertation thesis. Teheran: Faculty of management, university of Tehran.

Joarder, M. H. (2012). The role of HRM practices in predicting faculty turnover intention: empirical evidence from private universities in Bangladesh. The South East Asian Journal of Management.

Liden, R. C., Wayne, S. J., \& Sparrowe, R. T. (2000). An examination of the mediating role of psychological empowerment on the relations between the job, interpersonal relationships, and work outcomes. Journal of Applied Psychology, 85(3), 407.

Macey, W. H., \& Schneider, B. (2008). The meaning of employee engagement. Industrial and organizational Psychology, 1(1), 3-30.

Mahmud, K., \& Idrish, S. (2011). The impact of human resource management practices on turnover of bank employees in Bangladesh. World review of business research, 1(2), 71-83.

Maxwell, P. (2006). The vital 6: Findings from the 2005 CEO Magazine search. Hay Group Newsletter, 8-11.

Michaels, E., Handfield-Jones, H., \& Axelrod, B. (2001). War for Talent (Hardcover). Boston: Harvard Business School Press Books.

Nishii, L. H., Lepak, D. P., \& Schneider, B. (2008). Employee attributions of the "why" of HR practices: Their effects on employee attitudes and behaviors, and customer satisfaction. Personnel psychology, 61(3), 503545 .

Schaufeli, W. B., \& Bakker, A. B. (2004). Job demands, job resources, and their relationship with burnout and engagement: A multi-sample study. Journal of Organizational Behavior: The International Journal of Industrial, Occupational and Organizational Psychology and Behavior, 25(3), 293-315. 
Schuler, R. S., Jackson, S. E., \& Tarique, I. (2011). Global talent management and global talent challenges: Strategic opportunities for IHRM. Journal of world business, 46(4), 506-516.

Sekaran, U. (2003). Research methods for business, NY: John Wiley and Sons, Inc.

Simonton, D. K. (2011). Exceptional talent and genius.

Sobel, M. E. (1982). Asymptotic confidence intervals for indirect effects in structural equation models. Sociological methodology, 13, 290-312.

Stahl, G., Björkman, I., Farndale, E., Morris, S. S., Paauwe, J., Stiles, P., . . Wright, P. (2012). Six principles of effective global talent management. Sloan Management Review, 53(2), 25-42.

Tarique, I., \& Schuler, R. S. (2010). Global talent management: Literature review, integrative framework, and suggestions for further research. Journal of world business, 45(2), 122-133.

Taylor, M. S., Audia, G., \& Gupta, A. K. (1996). The effect of lengthening job tenure on managers' organizational commitment and turnover. Organization Science, 7(6), 632-648.

Thomas, K. (2009). Technical brief for the Work Engagement Profile: Content, reliability and validity. Mountain View, $C A$ : $C P P$.

Thomas, K., \& Tymon Jr, W. (2009). Work engagement profile. Cpp, Mountain View, Ca.

Thomas, K., \& Tymon, W. (1993). Empowerment Inventory. Tuxedo, NY: Xicom. Inc. DISTRIBUTION LIST.

Thomas, K. W., \& Tymon Jr, W. G. (1997). Bridging the motivation gap in total quality. Quality Management Journal, 4(2), 80-96.

Vaiman, V., Scullion, H., \& Collings, D. (2012). Talent management decision making. Management Decision, 50(5), 925-941. 